\title{
REVIEW
}

\section{Danon disease: focusing on heart}

\author{
Zhongwei Cheng and Quan Fang
}

Danon disease is a rare X-linked dominant lysosomal disease due to the primary deficiency of lysosome-associated membrane protein 2 (LAMP2) gene. Cardiomyopathy, skeletal myopathy and mental retardation are the typical triad of Danon disease. More than 60 LAMP2 mutations have been reported. The molecular mechanism is defects in LAMP2 protein (due to LAMP2 mutation) which causes insidious glycogen accumulation in cardiac muscle cells and resulting in cardiac hypertrophy and electrophysiological abnormalities. However, there are significant differences between the male and female Danon disease patients with regard to clinical features and cardiac manifestations. The clinical symptoms are variable, from asymptomatic to sudden cardiac death. Wolff-Parkinson-White syndrome is more common in male than female patients. Hypertrophic cardiomyopathy is predominant in male patients, whereas the similar prevalence of hypertrophic and dilated cardiomyopathy in female patients. Male patients are diagnosed usually at teenage, whereas the diagnosis and events occurred approximately 15 years later in female than male patients. Heart transplantation is the reliable treatment once the occurrence of heart failure and should be considered as early as possible due to its rapid progression.

Journal of Human Genetics (2012) 57, 407-410; doi:10.1038/jhg.2012.72; published online 14 June 2012

Keywords: Danon disease; echocardiography; electrocardiography; heart; molecular mechanism; treatment

Danon disease is an X-linked dominant lysosomal disease ${ }^{1}$ due to the primary deficiency of lysosome-associated membrane protein 2 (LAMP2) gene. ${ }^{2}$ Although apparently rare, the geographic distribution of Danon disease is wide, reported from the USA, Italy, Australia, Sweden, the UK, Japan and China. ${ }^{3-11}$ The pathological hallmark of the disease is intracytoplasmic vacuoles containing autophagic material and glycogen in cardiac (Figure 1) and skeletal muscle cells. ${ }^{1,12}$ The final diagnosis is based on the genetic analysis of LAMP2 gene. LAMP2 gene is located on Xq24, including nine exons (1-9a) and intron-exon junctions. ${ }^{13}$ More than 60 mutations of LAMP2 gene have been reported. The reported LAMP2 mutations in the past 10 years are summarized in Table 1. Cardiomyopathy, skeletal myopathy and mental retardation are the typical triad of Danon disease. ${ }^{5,14,15}$ The article will focus on heart, from molecular mechanism, clinical features to characteristics of electrocardiography and echocardiography as well as treatment.

\section{MOLECULAR MECHANISM}

Glucose enters cardiac muscle cells through transport proteins and undergoes phosphorylation by hexokinase, after which it is targeted for glycolysis or glycogen (a branched glucose polymer containing 93 percent $1-4$ glucose bonds and 7 percent branched $1-6$ glucose bonds, is a dynamic reservoir of energy for cardiac muscles) synthesis by glycogen synthase. Defects in glycogen degradation pathways (including lysosome activity) result in glycogen accumulation in cardiac muscle cells. Therefore, defects in LAMP2 protein (due to LAMP2 mutation) cause insidious glycogen accumulation, resulting in cardiac hypertrophy and electrophysiological abnormalities.

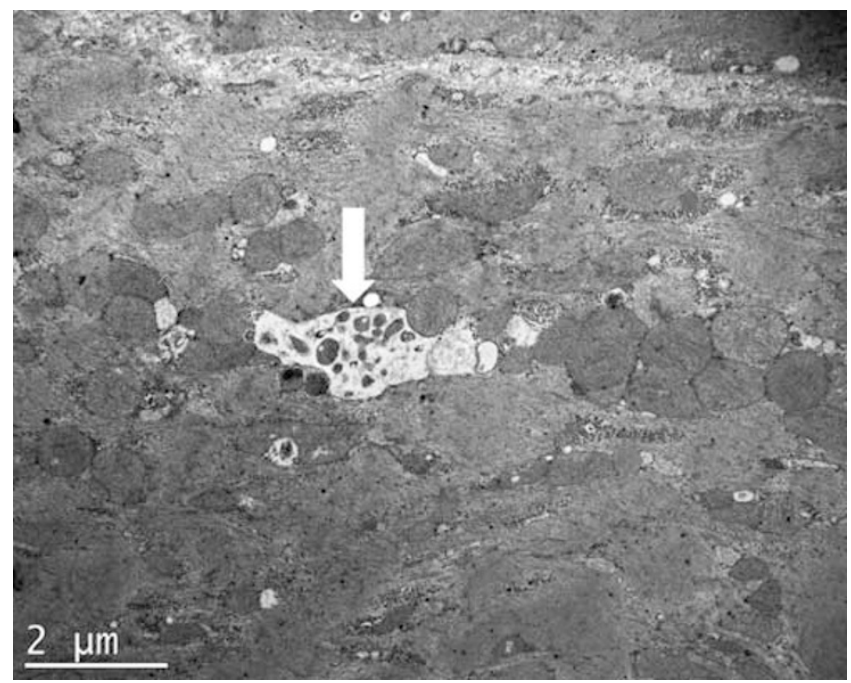

Figure 1 Electron microscopic examinations revealed the autophagic vacuole (arrow indicated) containing glycogen particles in cardiac muscle cells in one patient who underwent endomyocardial biopsy (magnification $\times 15000)$. 
Table 1 Reported mutations of LAMP2 gene in past 10 years $^{\mathrm{a}}$

\begin{tabular}{|c|c|c|c|}
\hline Authors & Mutation & Location & Mutation type \\
\hline \multirow[t]{3}{*}{ Cheng et al. ${ }^{3}$} & c.808_809 insG & Exon 6 & Frameshift \\
\hline & c.320_321 insCATC & Exon 3 & Frameshift \\
\hline & c.257_258deICC & Exon 3 & Frameshift \\
\hline Cottinet et al. ${ }^{4}$ & c. $864+1 \mathrm{delG}$ & IVS-6 & Splicing \\
\hline \multirow[t]{10}{*}{ Boucek et al. ${ }^{5}$} & c.-22_30delCGCCGCCGT & Promoter & - \\
\hline & c. $1-?, 64+?$ & Exon 1 & Large deletion \\
\hline & c. $64+1 \mathrm{G}>\mathrm{A}$ & IVS-1 & Splicing \\
\hline & c. $183+1 \mathrm{G}>\mathrm{A}$ & IVS-2 & Splicing \\
\hline & c. $247 \mathrm{C}>\mathrm{T}$ & Exon 3 & Stop codon \\
\hline & c.398-?_1233 + ?del & Exons 4-10 & Large deletion \\
\hline & c. $507 \mathrm{G}>\mathrm{A}$ & Exon 4 & Stop codon \\
\hline & c. $865-1 \mathrm{G}>\mathrm{C}$ & IVS-6 & Splicing \\
\hline & c. 1082 delA & Exon 8 & Frameshift \\
\hline & c.-1137-1140 del TATA/ins GCTGGTCCCAAT & Exon 9B & Insertion/deletion \\
\hline Kim et al. ${ }^{6}$ & c.241delG & Exon 3 & Frameshift \\
\hline Yang et al. ${ }^{7}$ & (TA)n simple repeat & $5^{\prime}$ UTR and exon 1 & microdeletion \\
\hline Toib et al. ${ }^{8}$ & c. $293 \mathrm{G}>\mathrm{A}$ & Exon 3 & Stop codon \\
\hline Sabourdy et al. ${ }^{9}$ & c.716delT & Exon 5 & Frameshift \\
\hline Regelsberger et al. ${ }^{10}$ & c.179 delC & Exon 2 & Frameshift \\
\hline Dougu et al. ${ }^{11}$ & c.573 delA & Exon 5 & Frameshift \\
\hline Di Blasi et al. ${ }^{17}$ & c. $1093+1 G>C$ & IVS-8 & Splicing \\
\hline lascone et al. ${ }^{18}$ & $\mathrm{c} .877 \mathrm{C}>\mathrm{T}$ & Exon 7 & Stop codon \\
\hline van der Kooi et al. ${ }^{19}$ & c. $1150 \mathrm{G}>\mathrm{C}$ & Exon $9 \mathrm{~B}$ & Missense \\
\hline Bui et al. ${ }^{20}$ & c. $864+3-6$ delGAGT & IVS-6 & Splicing \\
\hline Nadeau et al. ${ }^{21}$ & c. $865-3 C>A$ & IVS-6 & Splicing \\
\hline Tunon et al.22 & c. $1093+2 \mathrm{~T}>\mathrm{A}$ & IVS-8 & Splicing \\
\hline Taylor et al. ${ }^{23}$ & c.1219delA & Exon 8 & Frameshift \\
\hline \multirow[t]{3}{*}{ Fanin et al. ${ }^{24}$} & c.680_701del & Exon 5 & Frameshift \\
\hline & c.796_797insC & Exon 6 & Frameshift \\
\hline & c. $294 \mathrm{G}>\mathrm{A}$ & Exon 3 & Stop codon \\
\hline Echaniz-Laguna et al. ${ }^{25}$ & c.102_103 delAG & Exon 2 & Frameshift \\
\hline \multirow[t]{2}{*}{ Yang et al.26 } & c. $467 \mathrm{~T}>\mathrm{G}$ & Exon 4 & Stop codon \\
\hline & c. $1075 \mathrm{C}>\mathrm{T}$ & Exon 8 & Stop codon \\
\hline Balmer et al..27 & c. $138 \mathrm{G}>\mathrm{A}$ & Exon 2 & Stop codon \\
\hline Lobrinus et al..$^{28}$ & c. $470 \mathrm{C}>\mathrm{G}$ & Exon 4 & Stop codon \\
\hline Musumeci et al. ${ }^{29}$ & c.961 T>C & Exon 8 & Nonsynonymous \\
\hline \multirow[t]{6}{*}{ Arad et al..$^{15}$} & c. $64+1 G>T$ & IVS-1 & Splicing \\
\hline & c. $65 \_2 A>G$ & IVS-1 & Frameshift \\
\hline & c. $864+1-4$ del GTGA & IVS-6 & Splicing \\
\hline & c.865_2A $>G$ & IVS-6 & Frameshift \\
\hline & c. $928 \mathrm{G}>\mathrm{A}$ & Exon 7 & Missense \\
\hline & c. $327 \mathrm{~T}>\mathrm{A}$ & Exon 3 & Stop codon \\
\hline \multirow[t]{2}{*}{ Charron et al. ${ }^{30}$} & c.36_42delAGGGCTC & Exon 1 & Frameshift \\
\hline & c. $520 \mathrm{C}>\mathrm{T}$ & Exon 4 & Stop codon \\
\hline Horváth et al..$^{31}$ & c.929_1G > A & IVS-7 & Splicing \\
\hline Lacoste-Collin et al. ${ }^{32}$ & c.874_897del AACCGATTTTATCTGAAGGAAGTG & Exon 7 & Large deletion \\
\hline Takahashi et al. ${ }^{33}$ & c.883_884 insT & Exon 7 & Frameshift \\
\hline
\end{tabular}

aOnly the first report of the same mutation was listed.

\section{CLINICAL FEATURES}

The prevalence is significantly higher in men than women. ${ }^{5}$ Men are severely affected, and heart is involved in $88 \%$ male patients with the predominance of hypertrophic cardiomyopathy. ${ }^{5}$ Men have a high morbidity and are unlikely to reach the age of 25 years without a cardiac transplantation. ${ }^{14}$ Women are less severely affected, with an equal prevalence of dilated cardiomyopathy and hypertrophic cardiomyopathy. ${ }^{5}$ The average ages of first symptom, cardiac transplantation, and death are 12.1, 17.9 and 19.0 years in men and
27.9, 33.7 and 34.6 years in women, respectively; occurence of events was 15 years later in female than male patients. ${ }^{5}$ Symptoms are variable, from asymptomatic to sudden cardiac death (SCD). Palpitations and chest pain are the most common symptoms. Maron et al. ${ }^{14}$ reported seven Danon disease patients (six male) were classified New York Heart Association class I at cardiac diagnosis and recognized by virtue of heart murmur, family screening, abnormal electrocardiography or symptoms (chest pain and syncope); all the seven patients experienced serious adverse events 
during 8.6 \pm 2.6 years follow-up, including death of acute or progressive heart failure in four, SCD in two and heart transplantation in one. All the seven patients developed marked left ventricular (LV) systolic dysfunction (LV ejection fraction 25\% $\pm 7 \%$ ) with rapid deterioration with time interval from clinical stability to end stage of heart failure as brief as 6 months.

However, female patients have a different clinical course. Miani et al. ${ }^{16}$ reported six female patients showing a severe arrhythmogenic phenotype, including four patients who died suddenly (one aborted) at 37-54 years of age, and the other two patients underwent heart transplantation. Gene dosage probably accounts for the different clinical consequences of X-linked LAMP2 mutations in men as compared with women. ${ }^{15}$ Gene dosage also contributed to different clinical expression in men with different LAMP2 mutations, the partial function of mutant LAMP2 proteins may be preserved resulting from different LAMP2 mutations. ${ }^{15}$

\section{CHARACTERISTICS OF ELECTROCARDIOGRAPHY AND ECHOCARDIOGRAPHY}

Conduction abnormalities are very common in male patients, Cheng et al. ${ }^{3}$ reported two of three and Maron et al. ${ }^{14}$ reported five of six male patients having Wolff-Parkinson-White (WPW) syndrome with maximal LV voltage of $1.5-14.5 \mathrm{mV}$ as well as T-wave inversion. Toib et al. ${ }^{8}$ reported only one of seven and Miani et al. ${ }^{16}$ reported only two of six female patients with WPW syndrome. Boucek et al. ${ }^{5}$ summarized a total of 145 Danon disease patients, 68\% male and $27 \%$ female patients had a WPW pattern on electrocardiography.

The findings on echocardiography are different in male and female patients, male patients predominantly are having hypertrophic cardiomyopathy, Maron et al. ${ }^{14}$ reported the maximal LV thickness of $29-65 \mathrm{~mm}$ with normal LV ejection fraction and LV cavity dimensions at diagnosis, and evolved into dilated or enlarged during the follow-up. Cheng et al. ${ }^{3}$ reported all the three male patients with concentric LV hypertrophy with maximal LV thickness of 14-34 mm, normal LV ejection fraction and LV cavity dimensions at diagnosis. However, female patients had the equal prevalence of hypertrophic and dilated cardiomyopathy.

\section{TREATMENT}

Catheter ablation is an effective method for the abolishment of WPW syndrome. Boucek et al. ${ }^{5}$ reported half of the male and one third of the female patients underwent catheter ablation.

SCD is common in patients with Danon disease, especially in female patients. ${ }^{16}$ Implantable cardioverter defibrillator (ICD) implantation is one preventive treatment for SCD. Boucek et al. ${ }^{5}$ reported $41 \%$ male and $31 \%$ female patients received ICDs. However, ICD was less effective in patients with Danon disease than other cardiac disease (such as ischemic heart disease). Maron et al. ${ }^{14}$ reported that all the seven patients had received ICDs, which ultimately failed to terminate lethal ventricular tachyarrthymias in five. Heart transplantation significantly enhances the survival of patients with Danon disease, although only $17.6 \%$ patients underwent heart transplantation. ${ }^{5}$ Therefore, physicians should consider early intervention with heart transplantation once LV dysfunction occurs owing to the rapid progression of the disease. ${ }^{5,14}$

In conclusion, there are significant differences between male and female Danon disease patients with regard to clinical features and cardiac manifestations. WPW syndrome is more common in male than female patients. Hypertrophic cardiomyopathy is predominant in male patients, whereas the similar prevalence of hypertrophic and dilated cardiomyopathy in female patients. However, the clinical symptoms and events occurred approximately 15 years later in female than male patients. Heart transplantation is the reliable treatment once the occurrence of heart failure and should be considered as early as possible due to its rapid progression.

1 Danon, M.J., Oh, S.J., DiMauro, S., Manaligod, J.R., Eastwood, A., Naidu, S. et al. Lysosomal glycogen storage disease with normal acid maltase. Neurology 31, 51-57 (1981).

2 Nishino, I., Fu, J., Tanji, K., Yamada, T., Shimojo, S., Koori, T. et al. Primary LAMP-2 deficiency causes $\mathrm{X}$-linked vacuolar cardiomyopathy and myopathy (Danon disease). Nature 406, 906-910 (2000).

3 Cheng, Z., Cui, Q., Tian, Z., Xie, H., Chen, L., Fang, L. et al. Danon disease as a cause of concentric left ventricular hypertrophy in patients who underwent endomyocardial biopsy. Eur. Heart J. 33, 649-656 (2012).

4 Cottinet, S.L., Bergemer-Fouquet, A.M., Toutain, A., Sabourdy, F., MaakarounVermesse, Z., Levade, T. et al. Danon disease: intrafamilial phenotypic variability related to a novel LAMP-2 mutation. J. Inherit. Metab. Dis. 34, 515-522 (2011).

5 Boucek, D., Jirikowic, J. \& Taylor, M. Natural history of Danon disease. Genet. Med. 13, 563-568 (2011).

6 Kim, H., Cho, A., Lim, B.C., Kim, M.J., Kim, K.J., Nishino, I. et al. A 13-year-old girl with proximal weakness and hypertrophic cardiomyopathy with Danon disease. Muscle Nerve 41, 879-882 (2010).

7 Yang, Z., Funke, B.H., Cripe, L.H., Vick, 3rd G.W., Mancini-Dinardo, D., Peña, L.S. et al. LAMP2 microdeletions in patients with Danon disease. Circ.Cardiovasc. Genet. 3, 129-137 (2010).

8 Toib, A., Grange, D.K., Kozel, B.A., Ewald, G.A., White, F.V. \& Canter, C.E. Distinct clinical and histopathological presentations of Danon cardiomyopathy in young women. J. Am. Coll. Cardiol. 55, 408-410 (2010).

9 Sabourdy, F., Michelakakis, H., Anastasakis, A., Garcia, V., Mavridou, I., Nieto, M. et al. Danon disease: further clinical and molecular heterogeneity. Muscle Nerve 39, 837-844 (2009).

10 Regelsberger, G., Höftberger, R., Pickl, W.F., Zlabinger, G.J., Körmöczi, U., SalzerMuhar, U. et al. Danon disease: case report and detection of new mutation. J. Inherit. Metab. Dis. doi:10.1007/s10545-009-1097-9. (2009).

11 Dougu, N., Joho, S., Shan, L., Shida, T., Matsuki, A., Uese, K. et al. Novel LAMP-2 mutation in a family with Danon disease presenting with hypertrophic cardiomyopathy. Circ. J. 73, 376-380 (2009)

12 Sugie, K., Yamamoto, A., Murayama, K., Oh, S.J., Takahashi, M., Mora, M. et al. Clinicopathological features of genetically confirmed Danon disease. Neurology 58, 1773-1778 (2002)

13 Mattei, M.G., Matterson, J., Chen, J.W., Williams, M.A. \& Fukuda, M. Two human lysosomal membrane glycoproteins, h-lamp-1 and h-lamp-2, are encoded by genes localized to chromosome 13q34 and chromosome Xq24-25, respectively. J. Biol. Chem. 265, 7548-7551 (1990).

14 Maron, B.J., Roberts, W.C., Arad, M., Haas, T.S., Spirito, P., Wright, G.B. et al. Clinical outcome and phenotypic expression in LAMP2 cardiomyopathy. JAMA 301, 1253-1259 (2009).

15 Arad, M., Maron, B.J., Gorham, J.M., Johnson, Jr W.H., Saul, J.P., Perez-Atayde, A.R. et al. Glycogen storage diseases presenting as hypertrophic cardiomyopathy. N. Engl. J. Med. 352, 362-372 (2005).

16 Miani, D., Taylor, M., Mestroni, L., D’Aurizio, F., Finato, N., Fanin, M. et al. Sudden death associated with danon disease in women. Am. J. Cardiol. 109, 406-411 (2012).

17 Di Blasi, C., Jarre, L., Blasevich, F., Dassi, P. \& Mora, M. Danon disease: a novel LAMP2 mutation affecting the pre-mRNA splicing and causing aberrant transcripts and partial protein expression. Neuromuscul. Disord. 18, 962-966 (2008).

18 Iascone, M., lacovoni, A., Marchetti, D. \& Ferrazzi, P. Gene symbol: LAMP2. Disease: Danon disease. Hum. Genet. 123, 537 (2008).

19 van der Kooi, A.J., van Langen, I.M., Aronica, E., van Doorn, P.A., Wokke, J.H., Brusse, E. et al. Extension of the clinical spectrum of Danon disease. Neurology 70, 1358-1359 (2008).

20 Bui, Y.K., Renella, P., Martinez-Agosto, J.A., Verity, A., Madikians, A. \& Alejos, J.C. Danon disease with typical early-onset cardiomyopathy in a male: focus on a novel LAMP-2 mutation. Pediatr. Transplant 12, 246-250 (2008).

21 Nadeau, A., Therrien, C., Karpati, G. \& Sinnreich, M. Danon disease due to a novel splice mutation in the LAMP2 gene. Muscle Nerve 37, 338-342 (2008).

22 Tuñón, T., Guerrero, D., Urchaga, A., Nishino, I., Ayuso, T., Matsuda, Y. et al. Danon disease: a novel Lamp-2 gene mutation in a family with four affected members. Neuromuscul. Disord. 18, 167-174 (2008).

23 Taylor, M.R., Ku, L., Slavov, D., Cavanaugh, J., Boucek, M., Zhu, X. et al. Danon disease presenting with dilated cardiomyopathy and a complex phenotype. J. Hum. Genet. 52, 830-835 (2007).

24 Fanin, M., Nascimbeni, A.C., Fulizio, L., Spinazzi, M., Melacini, P. \& Angelini, C. Generalized lysosome-associated membrane protein-2 defect explains multisystem clinical involvement and allows leukocyte diagnostic screening in Danon disease. Am. J. Pathol. 168, 1309-1320 (2006).

25 Echaniz-Laguna, A., Mohr, M., Epailly, E., Nishino, I., Charron, P., Richard, P. et al. Novel Lamp-2 gene mutation and successful treatment with heart transplantation in a large family with Danon disease. Muscle Nerve 33, 393-397 (2006). 
26 Yang, Z., McMahon, C.J., Smith, L.R., Bersola, J., Adesina, A.M., Breinholt, J.P. et al. Danon disease as an underrecognized cause of hypertrophic cardiomyopathy in children. Circulation 112, 1612-1617 (2005).

27 Balmer, C., Ballhausen, D., Bosshard, N.U., Steinmann, B., Boltshauser, E., Bauersfeld, U. et al. Familial X-linked cardiomyopathy (Danon disease): diagnostic confirmation by mutation analysis of the LAMP2gene. Eur. J. Pediatr. 164, 509-514 (2005)

28 Lobrinus, J.A., Schorderet, D.F., Payot, M., Jeanrenaud, X., Bottani, A., Superti-Furga, A. et al. Morphological, clinical and genetic aspects in a family with a novel LAMP-2 gene mutation (Danon disease). Neuromuscul. Disord. 15, 293-298 (2005).

29 Musumeci, O., Rodolico, C., Nishino, I., Di Guardo, G., Migliorato, A., Aguennouz, M. et al. Asymptomatic hyperCKemia in a case of Danon disease due to a missense mutation in Lamp-2 gene. Neuromuscul. Disord. 15, 409-411 (2005).
30 Charron, P., Villard, E., Sébillon, P., Laforêt, P., Maisonobe, T., Duboscq-Bidot, L. et al. Danon's disease as a cause of hypertrophic cardiomyopathy: a systematic survey. Heart 90, 842-846 (2004)

31 Horváth, J., Ketelsen, U.P., Geibel-Zehender, A., Boehm, N., Olbrich, H., Korinthenberg, R. et al. Identification of a novel LAMP2 mutation responsible for X-chromosomal dominant Danon disease. Neuropediatrics 34, 270-273 (2003).

32 Lacoste-Collin, L., Garcia, V., Uro-Coste, E., Arné-Bes, M.C., Durand, D., Levade, T. et al. Danon's disease (X-linked vacuolar cardiomyopathy and myopathy): a case with a nove Lamp-2 gene mutation. Neuromuscul. Disord. 12, 882-885 (2002).

33 Takahashi, M., Yamamoto, A., Takano, K., Sudo, A., Wada, T., Goto, Y. et al. Germline mosaicism of a novel mutation in lysosome-associated membrane protein-2 deficiency (Danon disease). Ann. Neurol. 52, 122-125 (2002). 